\title{
Investigation of a New Installation for Improving the Efficiency of the Air-Cooled Condenser Fans in Thermal-Power Plants
}

\author{
Daqiang Yan, Jinghao Li, Weikun Ding \\ State Nuclear Power Software Development Center (SNPSDC) \\ National Energy Key Laboratory of Nuclear Power Software \\ South Park, Beijing Future Science \& Technology City, Changping District, Beijing, China \\ yandaqiang@snptc.com.cn; lijinghao@snptc.com.cn; dingweikun@snptc.com.cn
}

\begin{abstract}
A new installation for improving the efficiency of the air cooled condenser (ACC) heat exchange has been proposed in a patent and its performance is investigated in current paper. This installation can be used in air-cooled condenser power plants. The installation is simple and it is designed to be installed around ACC platform. The installation is called "ACC protecting shield". The performance of "ACC protecting shield" is investigated by CFD simulation. A series of wind environment conditions are simulated. The simulation results show that there would be significant improvements of the heat exchange efficiency when the installation is applied. The improvements include two aspects: first, flow rate of ACC fans would enhance. And second, plume recirculation would relieve. For $2 \mathrm{~m} / \mathrm{s}$ wind velocity condition, the average temperature of fans' inlet will drop remarkably (more than $0.78 \mathrm{~K}$ ), and the fans' flow rate will increase more than $1 \%$.
\end{abstract}

Keywords: air-cooled power plants; plume recirculation; fans' flow rate; CFD

\section{Background Introduction}

At present, thermal power is still major electricity generating form all over the world. Air cooled power plants is one major kind of thermal power plants. It is advisable to build air cooled power plants in the areas, where there are prolific of coal but lack of water [1]. It is essential to improve the air cooled condenser's efficiency, which plays a vital role in the electricity generating, power consumption saving and pollution controlling.

The air cooled power plant is shown in Fig1. On the air cooled condenser platform, there are many air cooled condensers (ACC). One air cooled condenser is amplified on the left corner in Fig1. Under the ACC, there are many fans drawing ambient air to flow through ACC [2], so that the exhausted air from the turbine can be cooled down in ACC. This is forced convection around ACC. The performance of thermal power plants will be good when the heat exchange efficiency between ACC and ambient air is high enough [3,4].

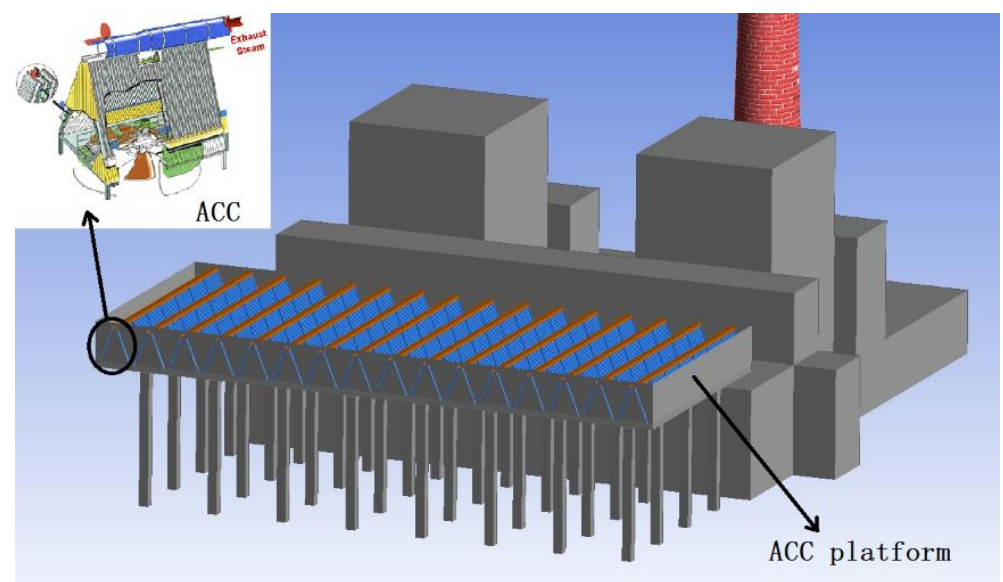

Fig. 1: thermal power plants and ACC. 
While sometimes undesired vortices would be produced by the ambient environment around ACC. It would lead plume recirculation [5]. Hot air may re-entered in the inlet of the fans under ACC. That would cause the efficiency of ACC heat exchange dropping.

So a new installation method for improving ACC heat exchange was proposed in a patent [7], and simulated by FLUENT in current paper. The results of the simulation confirm that heat exchange efficiency would increase substantially by use of the installation method. The new method is adding proper installation around ACC platform. The installation's goal is preventing plume recirculation and increasing fans' flow rate.

\section{Installation Introduction}

The new installation is called "protecting shield". The goal of "protecting shield" is to preventing plume recirculation and increasing flow rates of fans' inlet. "Protecting shield" is simple and its cross-section is shown in Fig3. Comparing traditional ACC's cross-section, the red line in Fig3 is the installation so called "protecting shield". And it is installed around ACC platform. The dimensions of "protecting shield" is also shown in Fig3. The material of "protecting shield" is suggested to be thermal insulation material.

"Protecting shield" has two function. First, it can block some plume recirculation to prevent hot air re-enter in the fans' inlet. Second, "protecting shield" can slow down air speed before air goes into fan, and induce the air flowing towards fans ventilation direction, so that the flow rate of fan would increase.

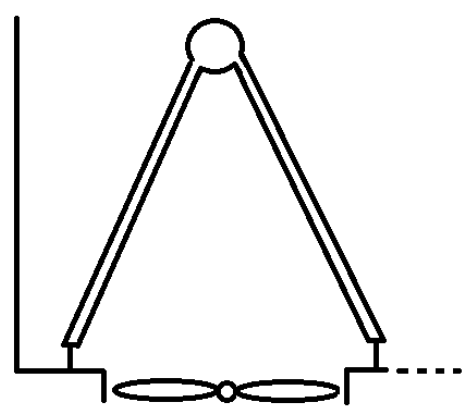

Fig. 2: Cross section of traditional ACC.

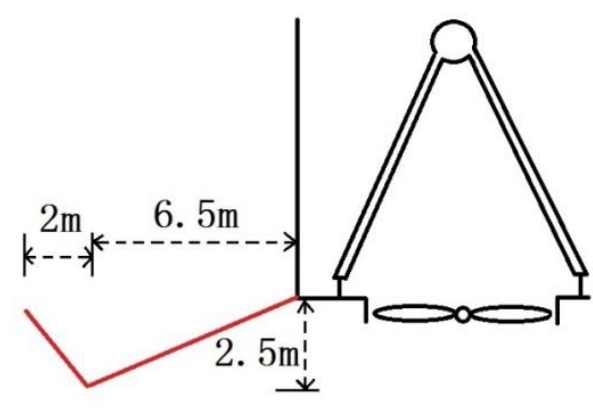

Fig. 3: cross section of "protecting shield" (red line).

Fig4 reveal the power plants applying the installation in 3D perspective. The installation around ACC platform is the "protecting shield" and it is highlighted by red colour in Fig4.

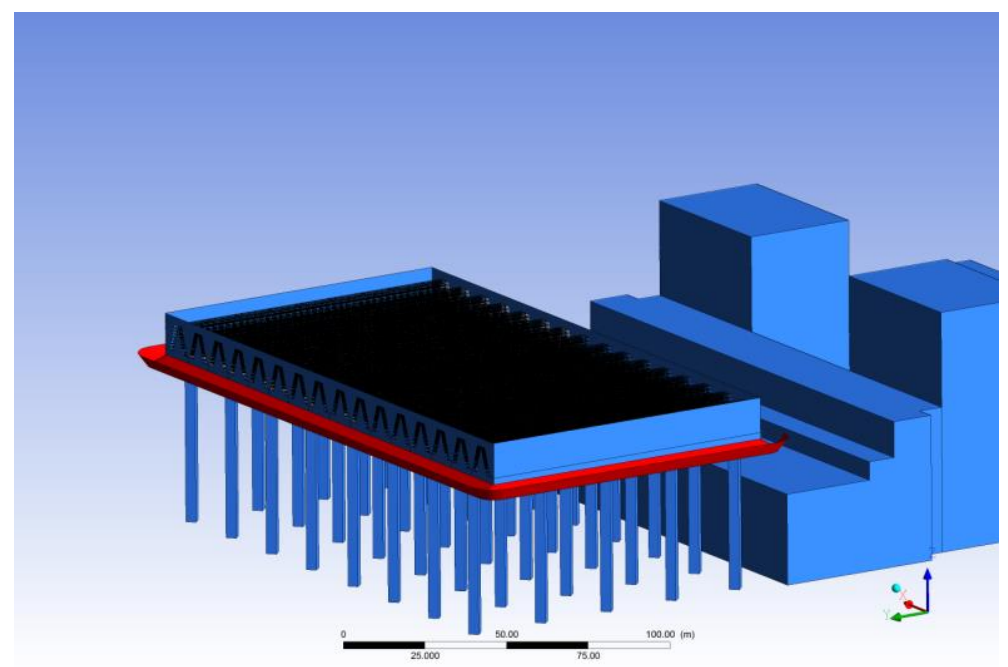

Fig. 4: Power plants applying "protecting shield" around ACC platform. 


\section{Simulation Methods}

CFD methods were used to investigate the effect of "protecting shield". $2 * 600 \mathrm{MW}$ air cooled power plants was investigated in this research.

Steady, homogeneous, incompressible model with the assumption of Boussinesq hypothesis is used in this simulation. Considering the k-epsilon turbulence, governing equations include N-S equations, k-epsilon turbulence equations and Boussinesq equation.

$2 * 600 \mathrm{MW}$ air cooled power plants is investigated in current paper. $2 * 600 \mathrm{MW}$ traditional power plants model is shown in Fig5. While power plants model that is installed "protecting shield" surrounding ACC platform is shown in Fig6.

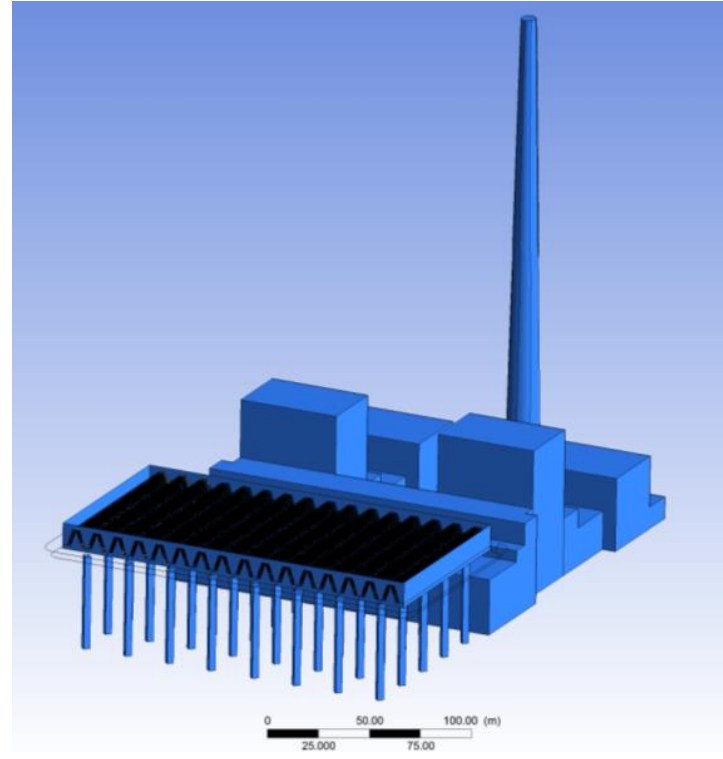

Fig. 5: Traditional model.

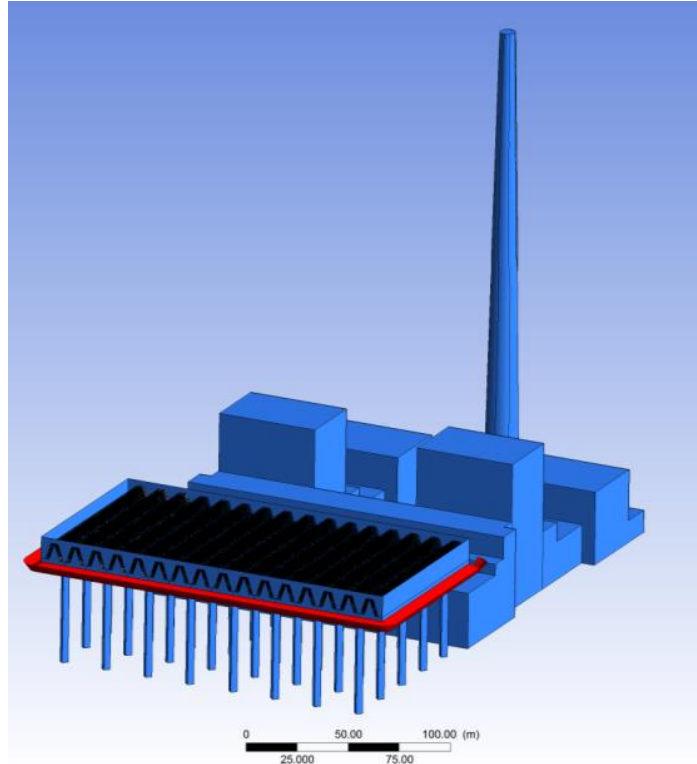

Fig. 6: Model with "protecting shield".

For $2 * 600 \mathrm{MW}$ air cooled power plants , there are $8 \times 8=64$ fans for one turbine unit, and there are 128 fans total for the two units. The arrangement of 128 fans is shown in Fig7. The average temperature of 128 fans and total flow rate had been calculated by CFD methods for different models and conditions.

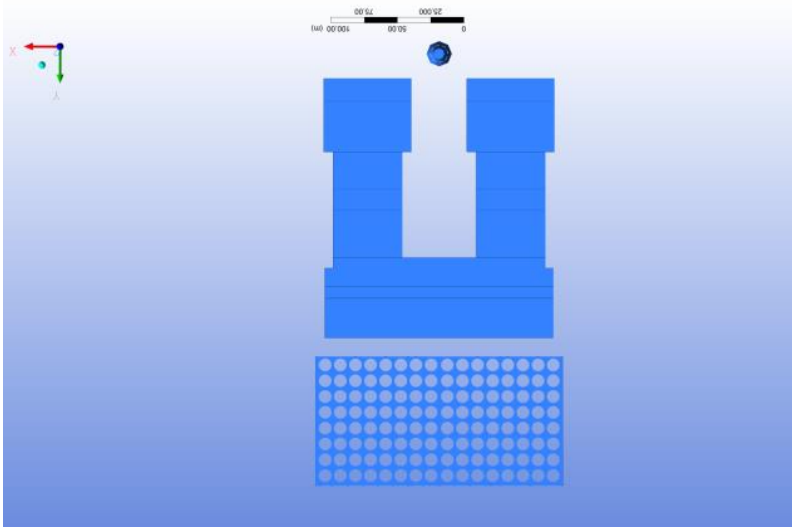

Fig. 7: The arrangement of 128 fans in top view of power plants.

FLUENT is used to simulate the 2 models. The two models shared the same mesh. When the traditional model is investigated, the "protecting shield" is set to be interior. Otherwise, the "protecting shield" is set to be wall condition. The 
mesh is generated by GAMBIT. The amount of grids is 1025558 . Velocity inlet boundary and pressure outlet boundary are set corresponding to the computational domain. The temperature of environment is $300 \mathrm{~K}$.

The air cooled condensers are set to be heat exchanger group in FLUENT solver. The fans were set to be fan condition. And others were all wall boundary conditions.

Two simulation condition are investigate to compare traditional power plants and power plants with "protecting shield". The two simulation are described in table1.

Table 1: Simulation condition.

\begin{tabular}{|l|l|l|}
\hline Simulation condition & Wind speed $(\mathrm{m} / \mathrm{s})$ & Wind direction \\
\hline 1 & 2 & 45 \\
\hline 2 & 2 & 90 \\
\hline
\end{tabular}

The wind direction in top view of power plants is identified in Fig8.

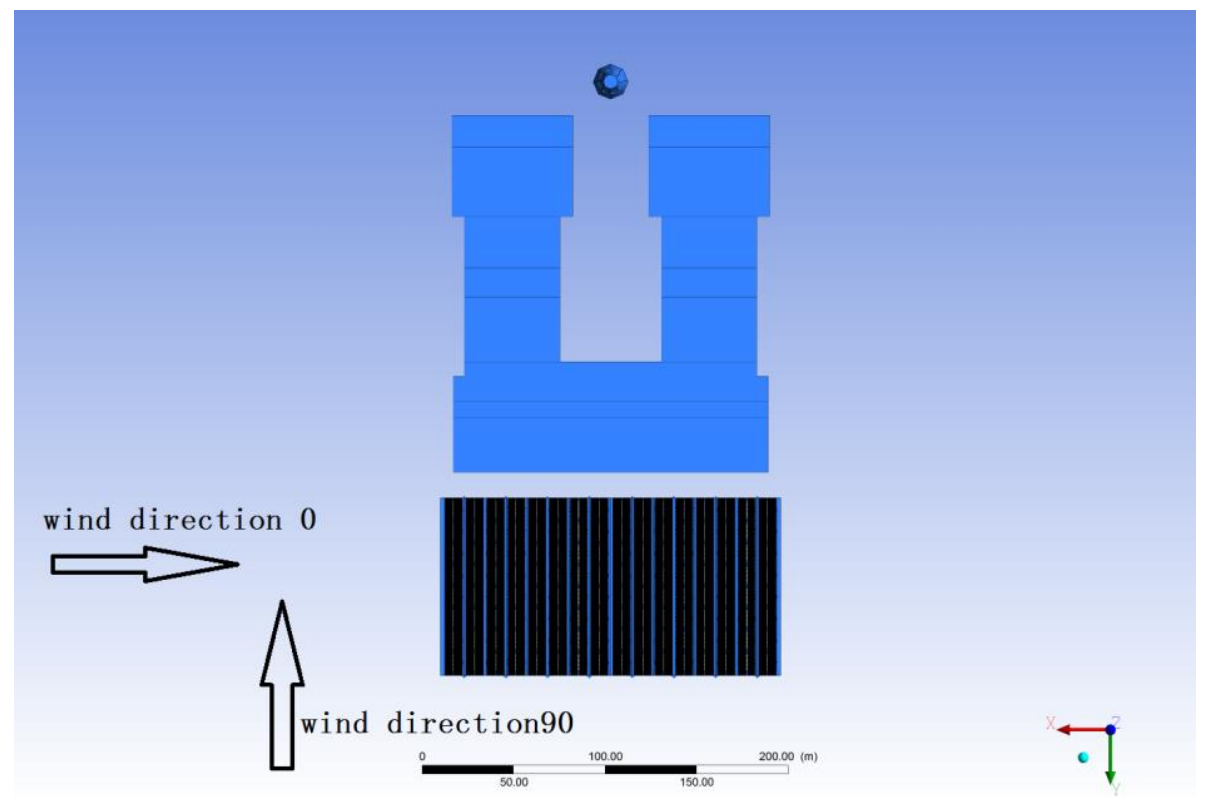

Fig. 8: Wind direction in top view of power plants.

The wind speed applied on inlet boundary in this research is the form of power-law equation: $\mathrm{u}=u_{10}(\mathrm{z} / 10)^{0.12}$

Where $\mathrm{u}_{10}$ is the wind speed at $10 \mathrm{~m}$ height, and defined as "wind speed" in Table1.

\section{Results and Discussion}

\subsection{Simulation Results}

The calculation results of the fans' performance are shown in table 2 and table 3 . The total flow rates of fans for two power plants models are listed in table 2. While the average temperature of fans' inlet is listed in table 3.

Table 2: Total flow rate $\left(\mathrm{m}^{\wedge} 3 / \mathrm{s}\right)$ for 2 models.

\begin{tabular}{|l|l|l|l|}
\hline condition & Traditional model $\left(\mathrm{Q}_{1}\right)$ & Model with “protecting shield" $\left(\mathrm{Q}_{2}\right)$ & Increasing rate \\
\hline 1 & 65868 & 66852 & $1.49 \%$ \\
\hline 2 & 65397 & 66519 & $1.72 \%$ \\
\hline
\end{tabular}


The increasing rate for total flow rates in table2 is defined as $\left(\mathrm{Q}_{2}-\mathrm{Q}_{1}\right) / \mathrm{Q}_{1}$.

Table 3: Average temperature of fans' inlet (T).

\begin{tabular}{|l|l|l|l|}
\hline condition & Traditional model $\left(\mathrm{T}_{1}\right)$ & Model with "protecting shield" $\left(\mathrm{T}_{2}\right)$ & reduction \\
\hline 1 & 301.39 & 300.38 & 1.01 \\
\hline 2 & 301.12 & 300.34 & 0.78 \\
\hline
\end{tabular}

The reduction of average temperature of fans' inlet in table 3 is defined as $\mathrm{T}_{1}-\mathrm{T}_{2}$

The results indicate that for condition 1 and 2, the average temperature of fans' inlet drops remarkably (about 0.78 or $1 \mathrm{~K})$, and the fans' flow rate increases more than $1 \%$. That indicates the installation would give positive effect to fans performance.

\subsection{Discussion}

Air flow driven by the fans would flow through air cooled condenser. Then hot plume would discharge from air cooled condenser, and flow upward vertically. Some part of the hot plume would flow downward and re-enter in fans' inlet, plume recirculation has generated. So the air temperature around ACC fans inlet is higher than environment temperature $(300 \mathrm{~K}$ in current paper). The performance of traditional power plants sufferes from this kind of plume recirculation. The hot plume recirculation is just like the flow vectors colored by temperature in Fig9 for traditional model in condition1. The plume recirculation for model with "protecting shield" in same condition is shown in Fig10. It can be seen that the plume recirculation phenomenon is relieved by "protecting shield" in Fig10 comparing with Fig9.

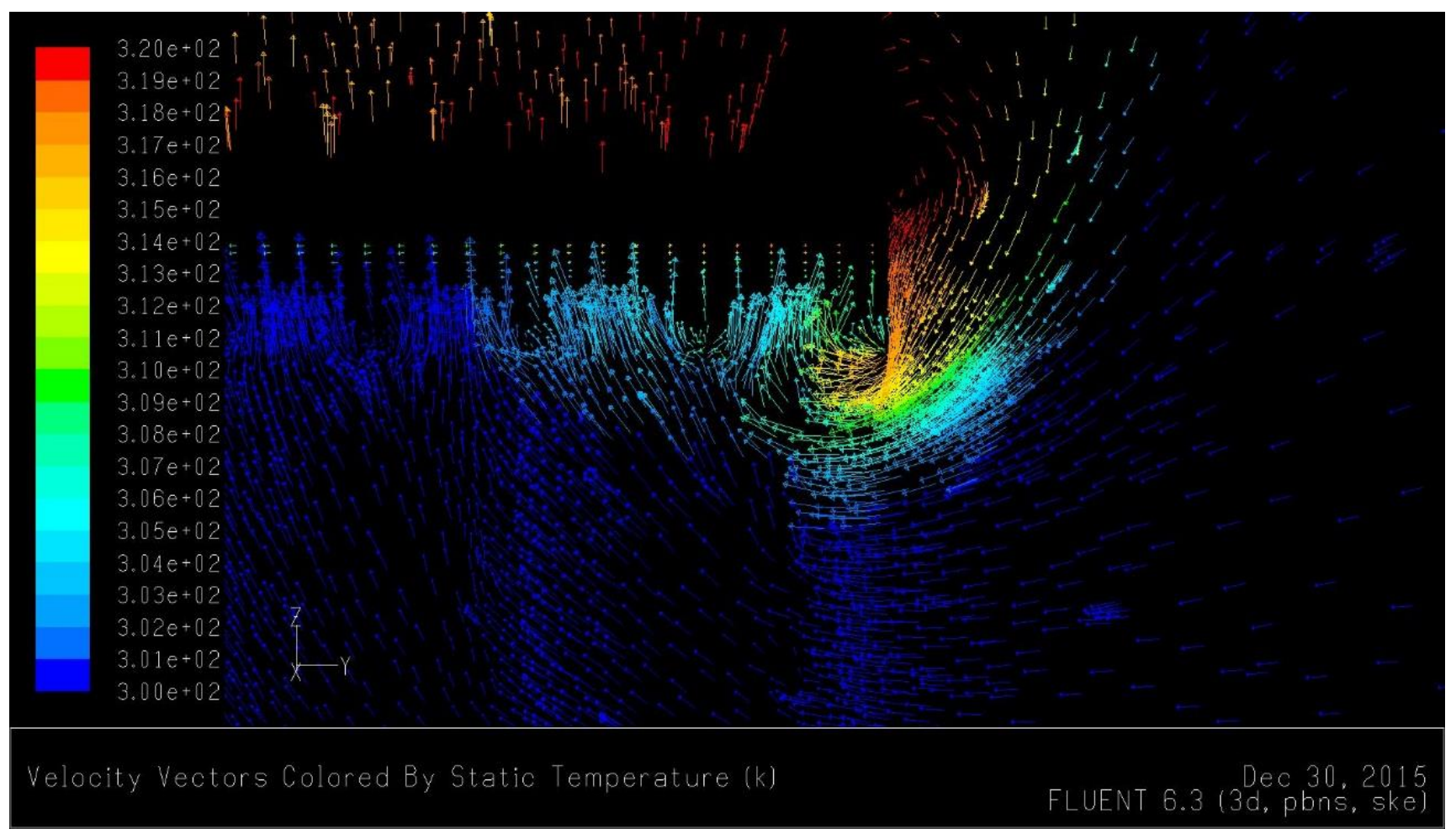

Fig. 9: Plume recirculation vectors colored by temperature for traditional power plants in condtion1. 


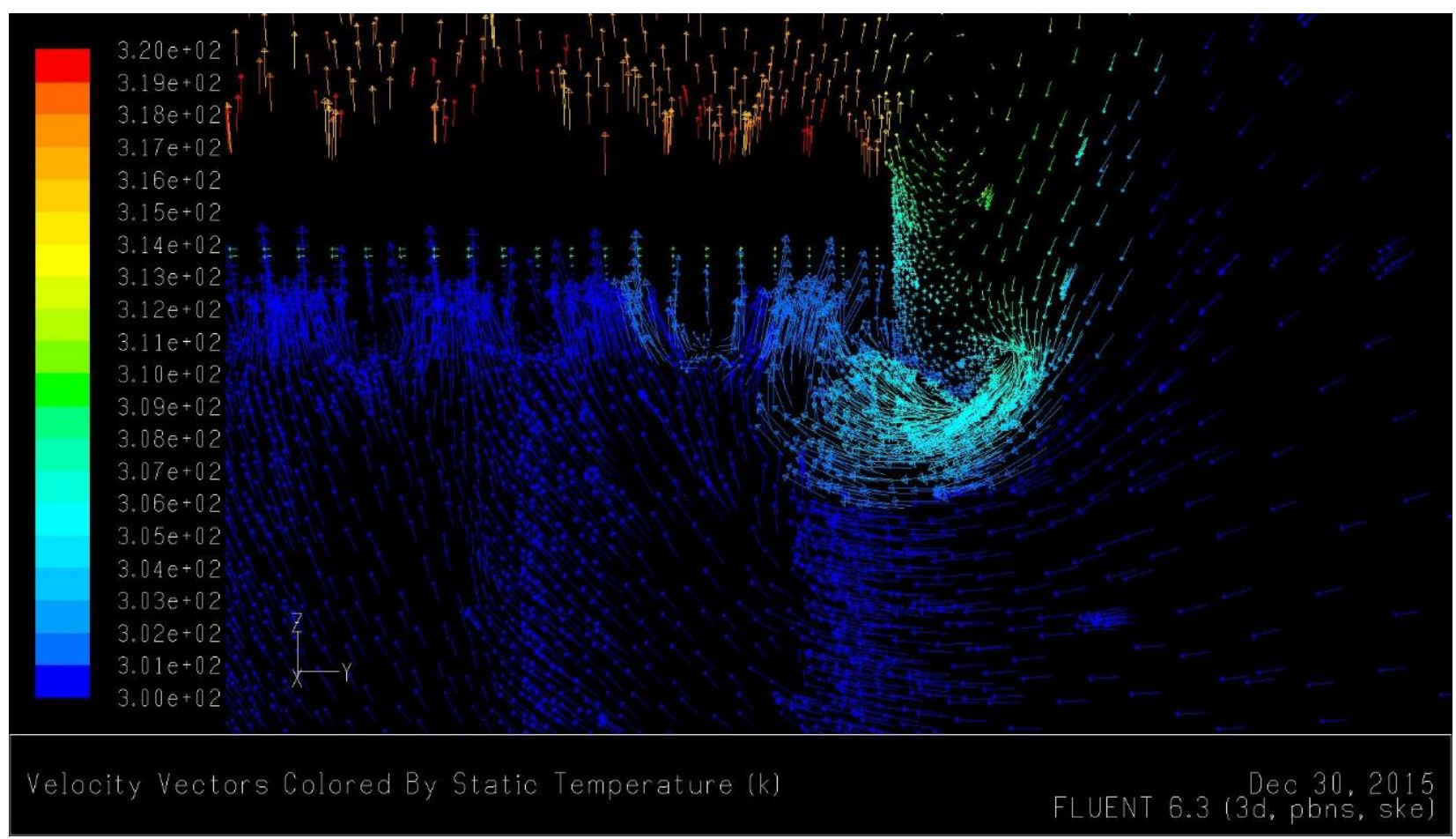

Fig. 10: Plume recirculation vectors colored by temperature for power plants with "protecting shield" in condtion 1.

Correspondingly, the temperature contours of fans inlet for the two models in condition 1 are shown in Fig 11 and Fig12 respectively. Comparison temperature contour of fans inlet between the two models indicates that the temperature is much lower for model with "protecting shield". That explains the temperature reduction results in Table3.

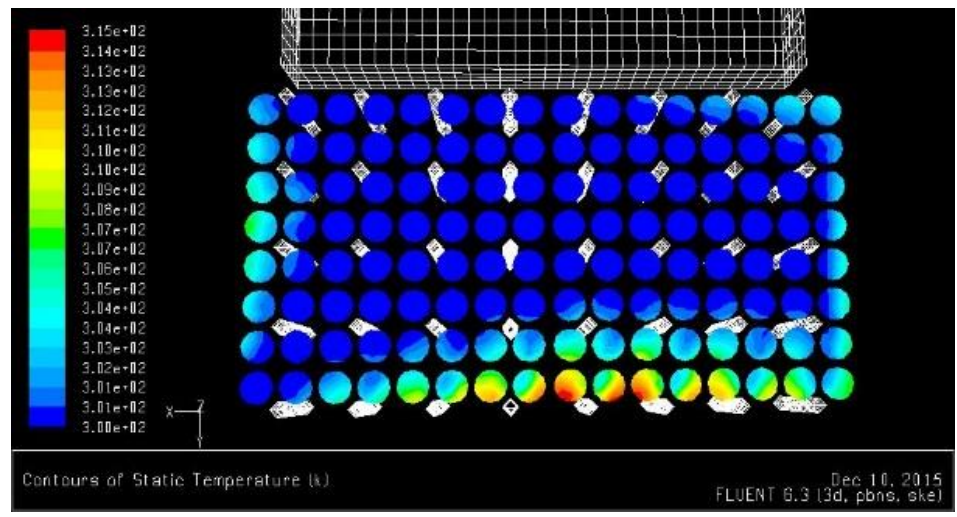

Fig. 11: fans' temperature contour for Traditional model in condtion 1 .

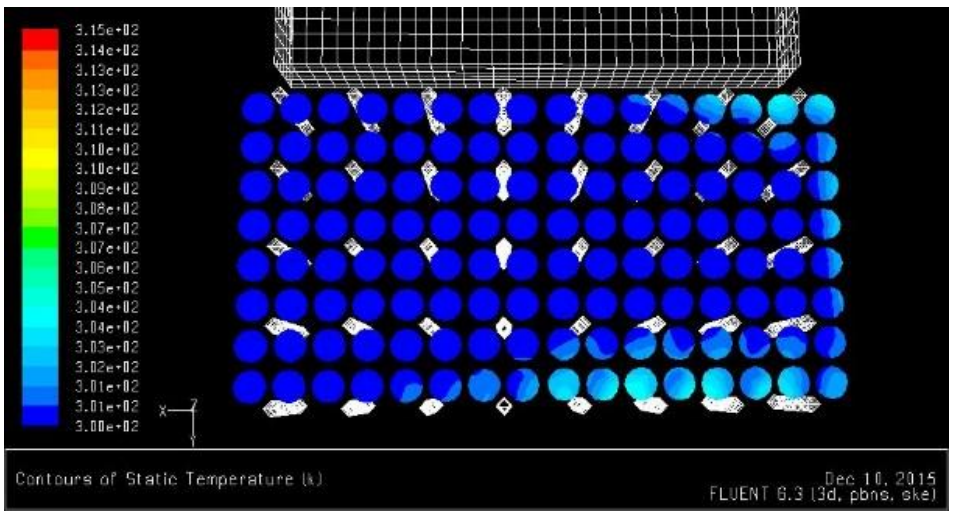

Fig. 12: fans' temperature contour for model with "protecting shield" in condition 1 .

The flow vectors coloured by vertical velocity for the two models in condition 2 are shown in Fig13 and Fig14. It can be seen that the air around ACC platform flowing downward or horizontally in Fig13. While for the model with "protecting shield" in Fig14, the air induced by "protecting shield" flowing upwards before entering fans inlet. That is of benefit to fans ventilation. As a result, the flow rate of fans would increase. The comparison between the two models explained the flow rates results in table2. 


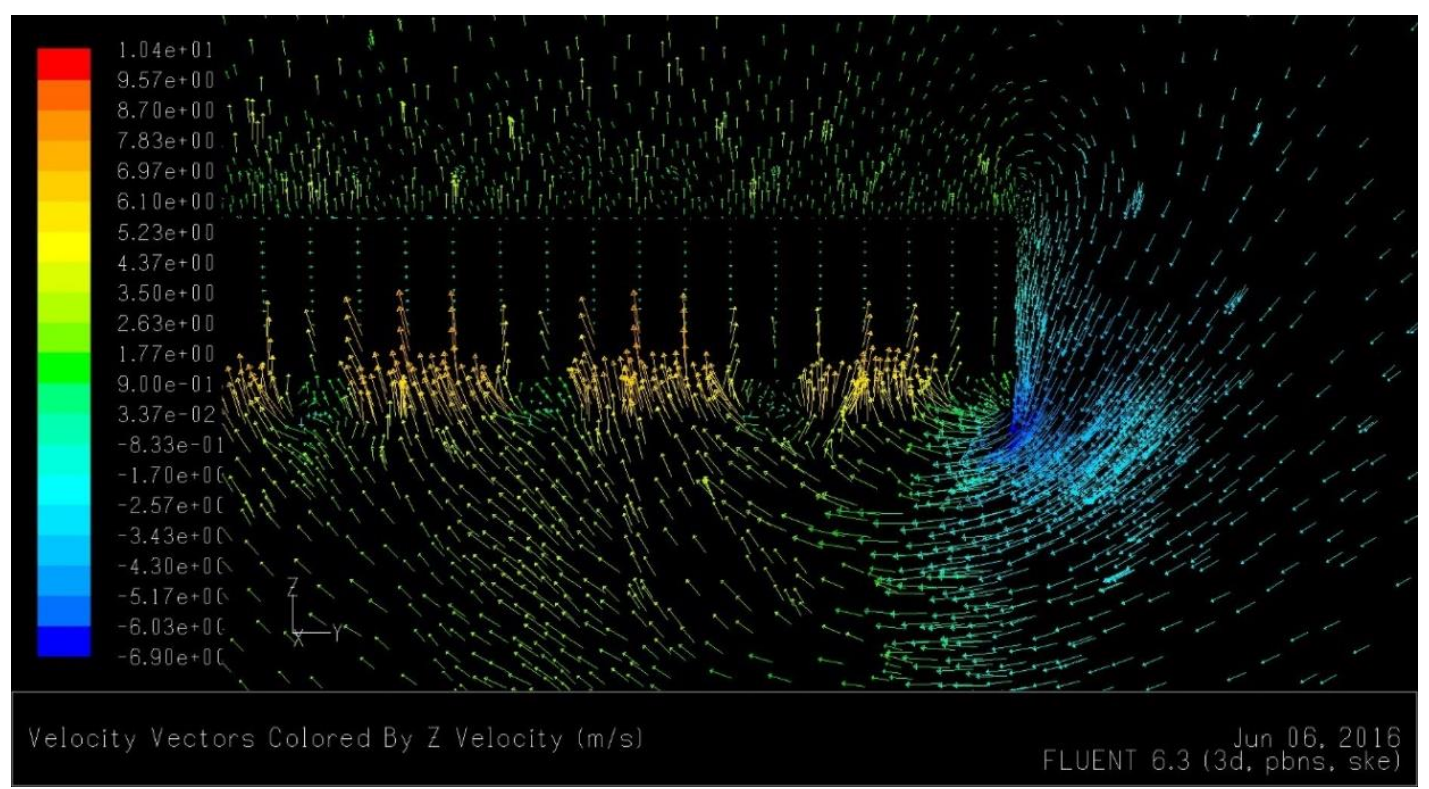

Fig. 13: Flow vectors(colored by Vz) for traditional model in condition2.

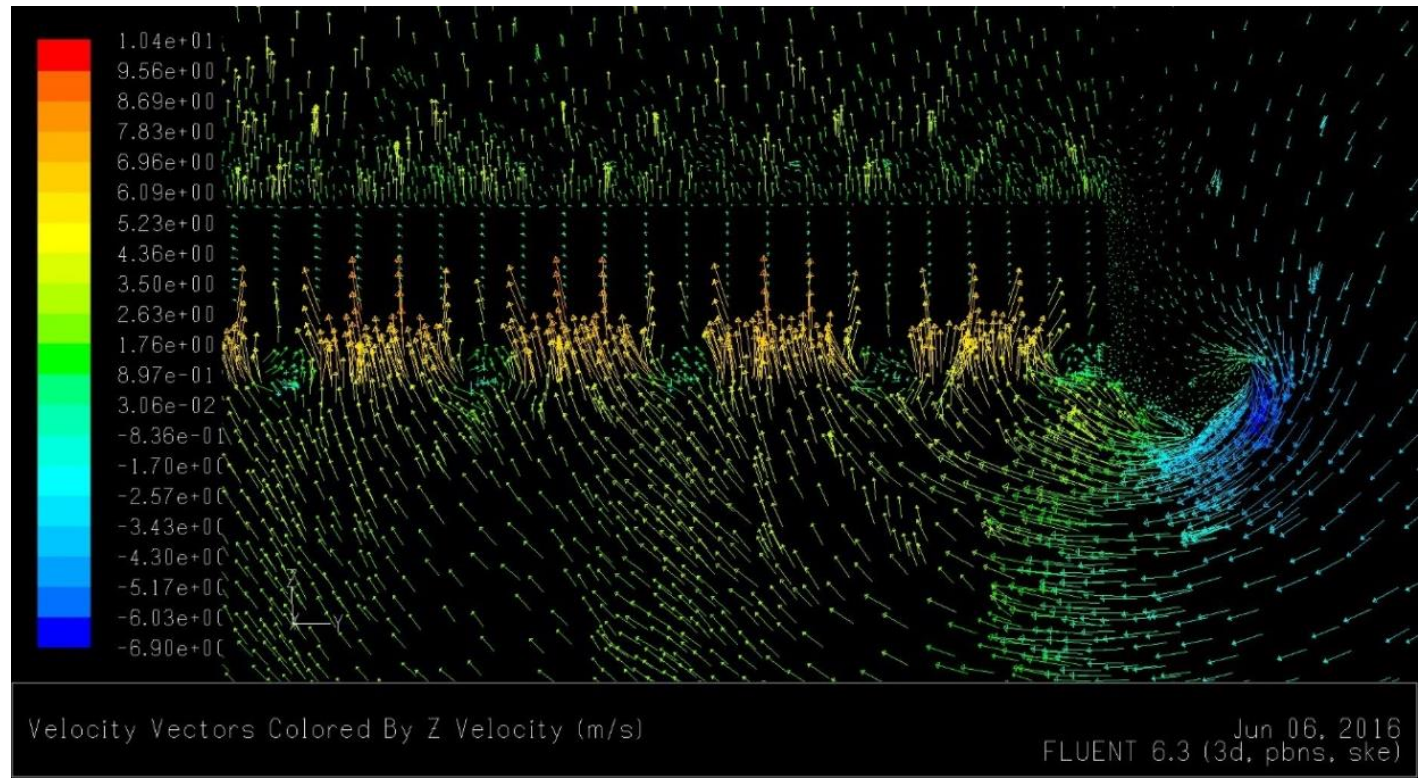

Fig. 14: Flow vectors(colored by Vz) for model with "protecting shield" in condition2.

\section{Conclusion}

One kind of simple installation so called "protecting shield" was proposed in a patent[7]. Applying "protecting shield" to power plants could improve ACC heat exchange efficiency. The improvement was investigated by use of CFD methods.

The flow field was analysed by comparing traditional power plants model and power plants with "protecting shield" model. The temperature contour and velocity vectors indicated that "protecting shield" can relieve plume recirculation effectively. "Protecting shield" would improve the 128 fans total flow rate up to $1.49 \%$ in condition 1 ( $2 \mathrm{~m} / \mathrm{s}$ environment wind velocity and flow direction 45), and meanwhile the average temperature of fans' inlet would drop 1.01K. For the same environment wind velocity, and wind direction 90 condition, the flow rate increasing rate would reach $1.72 \%$, and average temperature of fans' inlet would drop $0.78 \mathrm{~K}$.

In summary, this simple installation proposed in current paper would have positive effects to air cooled power plants. 


\section{Acknowledgements}

This work has been funded by the Chinese National Science and Technology Major Project under contract No. 2013ZX06004-008.

\section{References}

[1] K. R. Wilber and K. Zammit, "Development of procurement guidelines for air-cooled condensers," in Proceedings of the Advanced Cooling Strategies/Technologies Conference, Sacramento, California, 2005, pp. 1-24.

[2] C. J. Meyer, "Numerical investigation of the effect of inlet flow distortions on forced draught air-cooled heat exchanger performance," Applied Thermal Engineering. vol. 25, no. 11-12, pp. 1634-1649, 2005.

[3] L. J. Yang, X. Z. Du and Y. P. Yang, "Wind effect on the thermo-flow performances and its decay characteristics for air-cooled condensers in a power plant," Int. J. Therm. Sci. vol. 53, pp. 175-187, 2012.

[4] K. Duvenhage and D. G. Kroger, "The influence of wind on the performance of forced draft air-cooled heat exchangers," Journal of Wind Engineering and Industrial Aerodynamics, vol. 62, pp. 259-277, 1996.

[5] P. Liu, H. Duan and W. Zhao, "Numerical investigation of hot air recirculation of air cooled condensers at a large power plant," Applied Thermal Engineering, vol. 29, pp. 1927-1934, 2009.

[6] Z. Gu, H. Li, W. Zhang, Y. Li and J. Peng, "Wind tunnel simulation on re-circulation of air-cooled condensers of a power plant," Journal of Wind Engineering and Industrial Aerodynamics, vol. 93, pp. 509-520, 2005.

[7] Daqiang Yan, Jinghao Li and Yixue Chen, “Air cooled condenser system," Chinese Patent ZL $201420689698,2015$. 